\title{
Reduced Jet Velocity in Venous Flow after CSF Drainage: Assessing Hemodynamic Causes of Pulsatile Tinnitus
}

\author{
(D) H. Haraldsson, (D).R. Leach, (DE.I. Kao, (D)A.G. Wright, (DS.G. Ammanuel, DR.S. Khangura, (D) M.K. Ballweber, (DC.T. Chin, \\ (D) V.N. Shah, (DK. Meisel, DD.A. Saloner, and (D) M.R. Amans
}

\begin{abstract}
BACKGROUND AND PURPOSE: Idiopathic intracranial hypertension is commonly associated with transverse sinus stenosis, a venous cause of pulsatile tinnitus. In patients with idiopathic intracranial hypertension, CSF drainage via lumbar puncture decreases intracranial pressure, which relieves the stenosis, and may provide at least temporary cessation of pulsatile tinnitus. The objective of this study was to evaluate changes in venous blood flow caused by lowered intracranial pressure in patients with pulsatile tinnitus to help identify the cause of pulsatile tinnitus.
\end{abstract}

MATERIALS AND METHODS: Ten patients with suspected transverse sinus stenosis as a venous etiology for pulsatile tinnitus symptoms underwent MR imaging before and after lumbar puncture in the same session. The protocol included flow assessment and rating of pulsatile tinnitus intensity before and after lumbar puncture and MR venography before lumbar puncture. Post-lumbar puncture MR venography was performed in 1 subject.

RESULTS: There was a lumbar puncture-induced reduction in venous peak velocity that correlated with the opening pressure $(r=-0.72$, $P=.019)$ without a concomitant reduction in flow rate. Patients with flow jets had their peak velocity reduced by $0.30 \pm 0.18 \mathrm{~m} / \mathrm{s}(P=.002)$, correlating with a reduction in CSF pressure $(r=0.82, P=.024)$ and the reduction in subjectively scored pulsatile tinnitus intensity $(r=0.78$, $P=$.023). The post-lumbar puncture MR venography demonstrated alleviation of the stenosis.

CONCLUSIONS: Our results show a lumbar puncture-induced reduction in venous peak velocity without a concomitant reduction in flow rate. We hypothesize that the reduction is caused by the expansion of the stenosis after lumbar puncture. Our results further show a correlation between the peak velocity and pulsatile tinnitus intensity, suggesting the flow jet to be instrumental in the development of sound.

ABBREVIATIONS: $\mathrm{CE}=$ contrast-enhanced; $2 \mathrm{Dflow}=$ time-resolved $\mathrm{MR}$ velocimetry in a $2 \mathrm{D}$ plane; $4 \mathrm{Dflow}=$ time-resolved $\mathrm{MR}$ velocimetry in a $3 \mathrm{D}$ volume; $\mathrm{IIH}=$ idiopathic intracranial hypertension; $L P=$ lumbar puncture; $M R V=M R$ venography; $P T=$ pulsatile tinnitus

$\mathbf{P}$ ulsatile tinnitus (PT) is the auditory perception of a rhythmic, cardiac-synchronized, "whooshing" sound in the absence of an external source, which affects nearly 3 million

Received August 1, 2018; accepted after revision March 18, 2019.

From the Departments of Radiology and Biomedical Imaging (H.H., J.R.L., E.I.K. A.G.W., S.G.A., R.S.K., M.K.B., C.T.C., V.N.S., D.A.S., M.R.A.) and Neurology (K.M.), University of California, San Francisco, San Francisco, California; and Radiology Service (D.A.S.), VA Medical Center, San Francisco, California.

This work was supported by National Institutes of Health, R21DC016087 (M.R.A./D.A.S.).

Paper previously presented, in part, at: Annual Meeting of the Society for Magnetic Resonance Angiography, August 28-31, 2018; Glasgow, Scotland; and American Society of Neuroradiology Annual Meeting and the Foundation of the ASNR Symposium, June 2-7, 2018; Vancouver, British Columbia, Canada.

Please address correspondence to Matthew R. Amans, MD, MSc, Department of Radiology and Biomedical Imaging, UCSF, 505 Parnassus Ave, Room L349, San Francisco, CA 94143; e-mail: Matthew.Amans@ucsf.edu

- Indicates open access to non-subscribers at www.ajnr.org

http://dx.doi.org/10.3174/ajnr.A6043
Americans. ${ }^{1-4}$ The impact of PT is high due to difficulties in diagnosis, the health risks associated with the underlying causative diseases, and extremely common comorbid debilitating psychiatric illnesses. In addition, several of the anomalies that cause PT can have serious sequelae such as ischemic stroke, blindness, or intracranial hemorrhage..$^{5-7} \mathrm{PT}$ is often related to abnormal flow, including turbulence, in the blood vessels near the cochlea, but the exact mechanism of sound production remains elusive.

Idiopathic intracranial hypertension (IIH) is 1 cause of PT that carries a risk of developing blindness. Many patients with IIH have stenosis of 1 or both transverse sinuses at the junction with the sigmoid sinus, which may be caused by increased curvature of the tentorium cerebelli. ${ }^{8-10}$ Stent placement in usually 1 of these stenoses has been shown in prospective trials to both treat IIH and resolve patients' pulsatile tinnitus. ${ }^{11-14}$ In addition, lumbar puncture (LP) with removal of CSF temporarily decreases intracranial pressure and re- 


\begin{tabular}{ll} 
Acquisition & Parameters \\
\hline CE-MRV & FOV $=240 \times 180 \times 108 \mathrm{~mm}$, acq. matrix $=400 \times 286 \times 90$, acq. time $=66 \mathrm{sec}, \mathrm{TR}=5.0 \mathrm{~ms}, \mathrm{TE}=1.8 \mathrm{~ms}, \mathrm{FA}=30^{\circ}$, \\
& $\mathrm{SENSE}=2$ \\
4Dflow & $\mathrm{FOV}=240 \times 193 \times 34 \mathrm{~mm}$, acq. matrix $=184 \times 149 \times 24$, acq. time $=12 \mathrm{~min}, \mathrm{TR}=6.5 \mathrm{~ms}, \mathrm{TE}=2.9 \mathrm{~ms}, \mathrm{FA}=8^{\circ}$, \\
& $\mathrm{SENSE}=2$, segments $=3$, VENC $=1.5 \mathrm{~m} / \mathrm{s}$ \\
2Dflow & FOV $=160 \times 120 \mathrm{~mm}$, acq. matrix $=160 \times 120$, acq. time $=73 \mathrm{sec}, \mathrm{TR}=8.8 \mathrm{~ms}, \mathrm{TE}=5.4 \mathrm{~ms}, \mathrm{FA}=15^{\circ}$, segments $=2$, \\
& VENC $=0.75 \mathrm{~m} / \mathrm{s}$
\end{tabular}

Note:-acq. indicates acquisition; SENSE, sensitivity encoding; FA, flip angle; VENC, velocity encoding.

sults in a temporary improvement in the patients' IIH symptoms, including PT.

Recent advances in measuring the velocity field of blood flow in a $3 \mathrm{D}$ volume through the cardiac cycle using phase contrast $\mathrm{MR}$ imaging, referred to as 4Dflow, have allowed depiction of blood flow in the main cerebral outflow veins of patients. ${ }^{15-17}$ In this study, we used 4Dflow to try to determine the flow patterns that may be causing pulsatile tinnitus in patients with venous sinus stenoses who are suspected of having IIH. We performed flow analysis of the transverse sinus stenosis before and after removal of CSF via LP (which often at least temporarily resolves PT in patients with IIH). The aim of the study was the following: 1) to investigate whether flow jets, a potential source of turbulent flow, are present in symptomatic patients; 2 ) to see if these flow jets are reduced by reducing the intracranial pressure via LP; and 3) to determine whether the reduction in flow jets correlates with the improvement in PT sound intensity.

\section{MATERIALS AND METHODS}

We prospectively performed MR imaging of adult patients with a suspected venous etiology of pulsatile tinnitus before and after MR imaging-guided LP with removal of as much as $20 \mathrm{~mL}$ of CSF using a study protocol approved by the Institutional Review Board at UCSF. All patients signed written informed consent to participate in this study.

\section{Patient Selection}

Ten patients with PT and suspected IIH and venous etiology of PT were recruited from the University of California, San Francisco Pulsatile Tinnitus Clinic, a multispecialty clinic that evaluates patients with PT. PT was suspected to be of venous etiology if a patient described a low-pitched, pulse-synchronous sound that improved with ipsilateral neck compression, and potential arterial (or other) causes such as carotid atherosclerosis, fibromuscular dysplasia, tumor, or dural arteriovenous fistula were not identified on noninvasive imaging. Patients were suspected of having IIH if they had symptoms of IIH and an MR imaging that excluded intracranial mass, but had findings suggestive of IIH (including transverse sinus stenosis, optic nerve sheath distension or kinking, and a partially empty and expanded sella).

\section{Experimental Protocol}

Pre-LP MR imaging, MR imaging-guided LP, and post-LP MR imaging were performed consecutively in an interventional MR imaging suite using a 1.5T MR imaging system. None of the subjects were administered anxiolytic or analgesic medications before the LP or MR imaging. A summary of the MR imaging parameters is shown in Table 1.

The pre-LP MR imaging examination started with a low-res- olution timing run performed after a 2-mL Gd-DTPA bolus followed by a $20-\mathrm{mL}$ saline flush (both administered at $2 \mathrm{~mL} / \mathrm{s}$ ) to determine the transit time from the injection site to the jugular vein. A contrast-enhanced MR venography (CE-MRV) was then acquired, timed to the venous phase as determined by the timing run. That study used a high-resolution CE-MR venogram with a 20-mL Gd-DTPA bolus followed by a 20-mL saline flush (both administered at $2 \mathrm{~mL} / \mathrm{s}$ ). For 1 patient, Gd-DTPA was replaced with ferumoxytol. In accordance with our institutional guidelines, $12 \mathrm{~mL}$ of ferumoxytol was infused slowly for 20 minutes before the MR imaging acquisition, and the timing run was not performed. Following the CE-MR venogram, sinus flow rates were acquired with time-resolved MR velocimetry in a $2 \mathrm{D}$ plane (2Dflow) in planes perpendicular to the sigmoid sinuses just distal to their junctions with the jugular veins. Finally, the velocities in the sinuses were measured using 4 Dflow acquired in a slab covering the transverse and sigmoid sinuses.

Before LP, patients were asked to rate their PT symptoms on a $0-10$ Likert scale. Ten was rated as the sound intensity of a passing train, 6 was the intensity of a typical conversation in a restaurant, and 0 was no symptoms at the time of evaluation. LP was performed under MR imaging guidance on the MR imaging table of the interventional MR imaging suite. Opening pressure was measured with subjects lying in the decubitus position with legs relaxed. IIH was diagnosed by the modified Dandy criteria as opening pressure of $>25 \mathrm{~cm} \mathrm{H}_{2} \mathrm{O} .{ }^{18}$ Patients had $20 \mathrm{~mL}$ of CSF withdrawn, which was sent for routine laboratory analysis if the opening pressure was $\geq 25 \mathrm{~cm} \mathrm{H}_{2} \mathrm{O}$. Closing pressure was measured after removal of CSF. Patients were asked to again rate their PT on the same $0-10$ scale after CSF removal.

Following the LP, a post-LP MR imaging acquisition included 2D- and 4Dflow as previously described. Furthermore, the prolonged intravascular residence time of ferumoxytol of $>12$ hours ${ }^{19,20}$ permitted a repeat post-LP CE-MR venogram for 1 patient without administration of an additional contrast agent. $^{21}$

\section{Flow Postprocessing}

The peak velocity at several locations along the ipsilateral sinuses was obtained using in-house software, schematically described in Fig 1. Postprocessing begins with contouring the transverse and sigmoid sinuses on the symptomatic side from the CE-MRV. This is followed by a phase-offset background correction to the 4Dflow and registering the CE-MRV contour to both the pre- and post-LP $4 \mathrm{Dflow}$. Then, the centerline of the contoured lumen is extracted, and cross-sectional cut planes are generated at 1-mm intervals along the flow lumen. Last, peak velocities are extracted from each of the cut planes along the centerline across time. The 

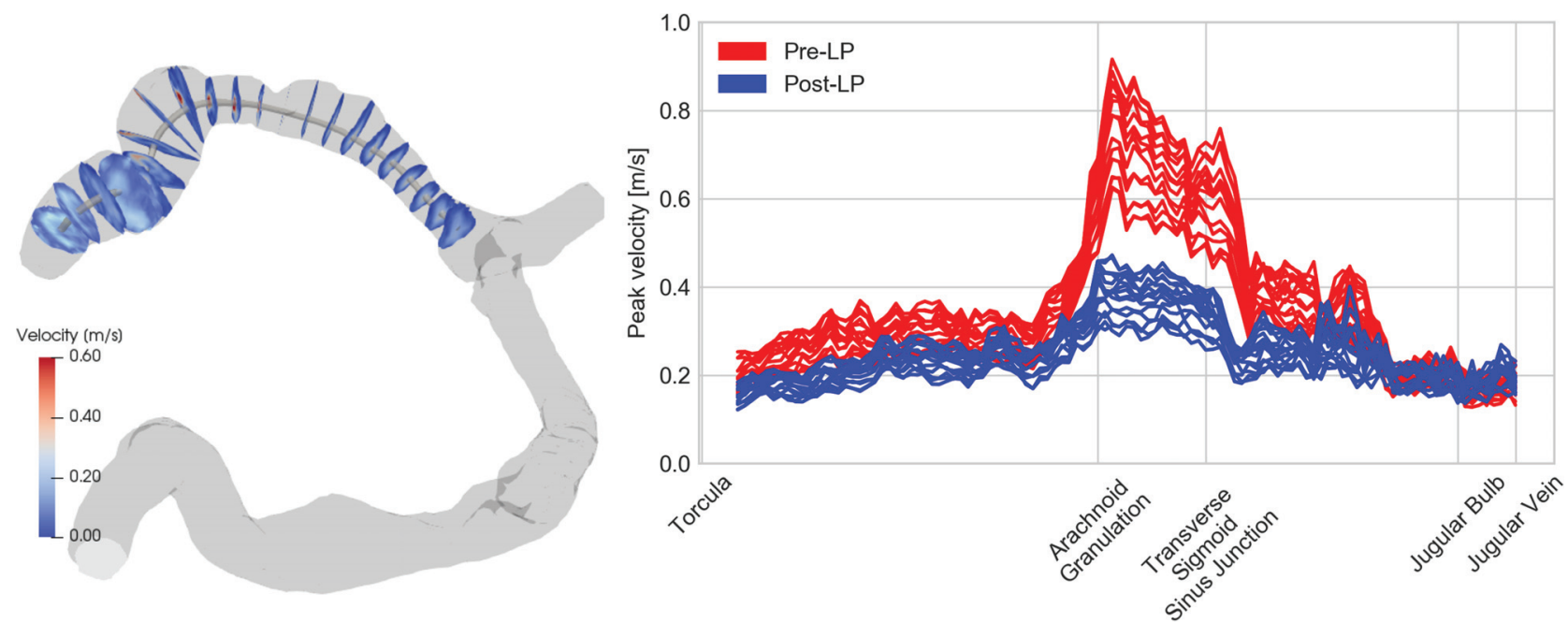

FIG 1. Left, MR venogram (gray) of the bilateral transverse and sigmoid sinuses showing the centerline and transverse cut planes. Right, The peak velocity along the centerline is plotted for different time points in the cardiac cycle before (red) and after (blue) LP.

Table 2: Summary of patients ${ }^{\mathrm{a}}$

\begin{tabular}{lccc}
\hline & Pre-LP & Post-LP & P Value \\
\hline Pressure $\left(\mathrm{cm} \mathrm{H}_{2} \mathrm{O}\right)$ & $21.7 \pm 5.2$ & $8.9 \pm 2.0$ & $<.001$ \\
PT intensity & $4.4 \pm 3.2$ & $1.7 \pm 2.5$ & .020 \\
Ipsilateral flow rate $(\mathrm{mL} / \mathrm{min})$ & $393 \pm 100$ & $406 \pm 92$ & .296 \\
Ipsilateral peak velocity $(\mathrm{m} / \mathrm{s})$ & $0.98 \pm 0.37$ & $0.73 \pm 0.25$ & .003 \\
CSF withdrawn $(\mathrm{mL})$ & \multicolumn{2}{c}{$14.9 \pm 6.4$} \\
Severity of stenosis & \multicolumn{2}{c}{$77.9 \pm 28.0$} \\
\hline
\end{tabular}

${ }^{a}$ Data are means unless otherwise indicated.

peak velocity of $>0.5 \mathrm{~m} / \mathrm{s}$ visually matched the appearance of a flow jet, so this velocity was used as a threshold value to determine the presence of jets.

Flow rates were quantified using Segment (http://segment. heiberg.se $)^{22}$ to evaluate the 2 Dflow data acquired through the sigmoid sinus.

\section{Statistical Analysis}

Linear regression was performed to investigate the relation between the opening pressure and the change in peak velocity caused by the CSF drainage. To investigate potential confounding characteristics, we used ANOVA to test whether linear regression models with 2 variables were better than a model using the opening pressure alone. The additional variables investigated were flow rate, stenosis severity, change in CSF pressure, and the amount of CSF drained.

Statistical analysis was performed on both the group as a whole but also on the subgroup of patients with ipsilateral flow jets, which depict the impact for PT with suspected flow jet etiology.

Paired $t$ tests were used to detect changes in intracranial pressure, flow rate, and velocities before and after lumbar puncture. The Pearson product momentum correlation was used to determine whether a reduction in peak velocity correlated with the reduction in intracranial pressure, and it was also used to determine whether the reduction in peak velocity correlated with the reduction in PT sound intensity.

\section{RESULTS}

Ten patients were included in the study. Seven of the 10 patients did not meet the diagnostic criteria for $\mathrm{IIH}^{8} ; 2$ were PT asymp- tomatic at the time of the pre-LP query; an ipsilateral jet with peak velocity of $>0.5 \mathrm{~m} / \mathrm{s}$ was identified in 8 of the 10 patients; and 1 patient underwent placement of a lumbar drain preventing recording of the closing pressure. A summary of the patient information is provided in Table 2 .

There was a correlation between the change in ipsilateral peak velocity and the opening pressure $(r=$ $-0.72, P=.019$ for all patients, Fig 2 , and $r=-0.80, P=.030$ for patients without IIH). No confounding characteristics were found by adding a second variable to the linear regression in addition to the opening pressure: flow rate $(P=.208)$, stenosis severity $(P=.375)$, change in CSF pressure $(P=.543)$, and the amount of CSF drained $(P=.529)$.

No correlation was found between opening pressure and the change in the ipsilateral flow rate $(r=0.21, P=.564)$. There was also a correlation between the change in the PT rating and the reduction in peak velocity $(r=0.67, P=.035)$. The severity of the stenosis was not found to correlate with peak velocity $(r=0.50, P=.146)$ or a change in peak velocity $(r=-0.40$, $P=.258)$.

\section{Patients with an Ipsilateral Jet}

Eight of 10 patients had an ipsilateral flow jet, as illustrated in Fig 3. Two of these were asymptomatic at the time of the pre-LP query. The lumbar puncture reduced CSF pressure by a mean of $12.8 \pm 3.4 \mathrm{~cm} \mathrm{H}_{2} \mathrm{O}(P<.001)$ without significant changes in the ipsilateral bulk flow rate $(P=.479)$. Nevertheless, the peak velocity was reduced by a mean of $0.30 \pm 0.18$ $\mathrm{m} / \mathrm{s}(P=.002)$. The reduction in peak velocity correlated with the reduction in pressure $(r=0.82, P=.024)$ and with the reduction in subjectively scored $\mathrm{PT}$ intensity $(r=0.78, P=$ $.023)$. The hemodynamic relations for these patients are illustrated in Fig 4.

The 6 patients experiencing pre-LP PT symptoms reported a mean PT intensity reduction of $3.8 \pm 3.4$. 


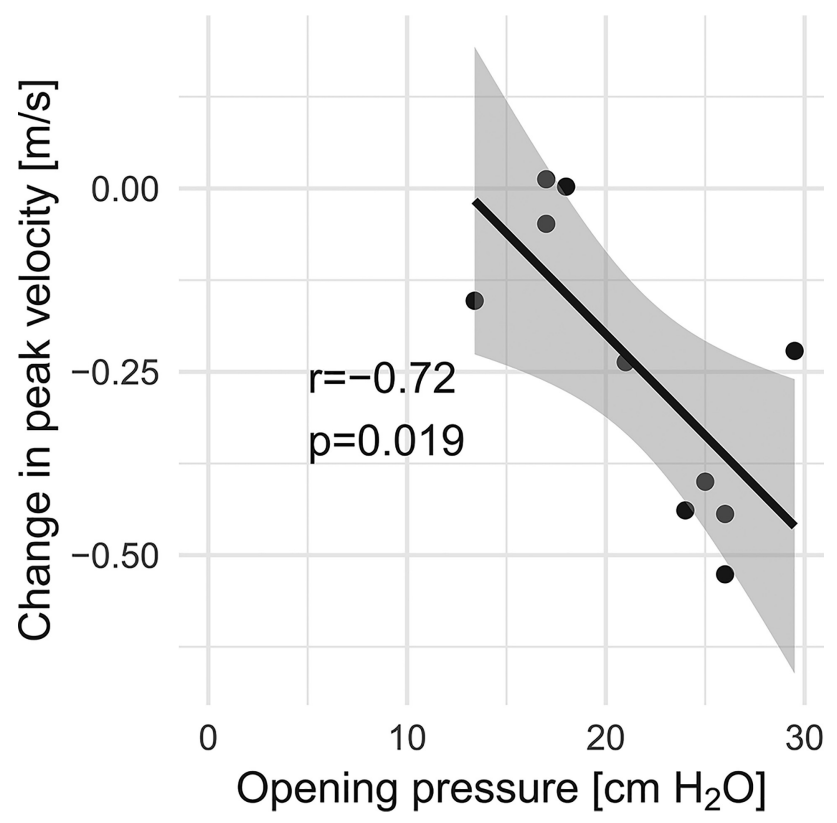

FIG 2. Lumbar puncture-induced change in ipsilateral peak velocity in relation to opening pressure.

Pre-LP

Post-LP
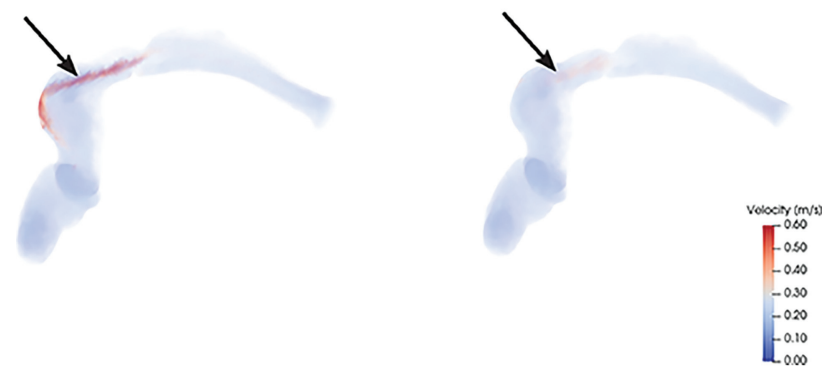

FIG 3. The left side shows an ipsilateral flow jet pre-LP that is weakened post-LP without a concomitant change in the flow rate (374-381 $\mathrm{mL} / \mathrm{min})$. The rating of PT intensity for this patient was reduced from 9 to 0.

\section{Patients without an Ipsilateral Jet}

Two patients did not have an ipsilateral flow jet. The first of these patients had a contralateral jet of reduced peak velocity after lumbar puncture $(0.61 \mathrm{~m} / \mathrm{s}$ from $0.67 \mathrm{~m} / \mathrm{s}$ pre-LP), matching the mild improvement of the PT intensity ( 4 to 3 ). The second patient had high velocities in the external carotid artery, which subsided after LP, qualitatively matching the reduction in PT intensity (decreasing from 3 to 0 ).

\section{Pre- and Post-LP MRV}

The patient imaged using ferumoxytol contrast underwent both pre- and post-LP CE-MR venography studies, demonstrating near-complete resolution of transverse sinus stenosis at a lower CSF pressure ( $10 \mathrm{~cm} \mathrm{H}_{2} \mathrm{O}$ from $25 \mathrm{~cm} \mathrm{H}_{2} \mathrm{O}$ before LP) (Fig 5).

\section{DISCUSSION}

The aim of this study was to investigate changes in venous sinus flow features and PT intensity in response to lumbar puncture. The key findings in this study were the following: 1) Flow jets were seen in most cases in this study; 2) lowering the CSF pressure decreased the peak velocity of the flow jet in a venous sinus stenosis, without a concomitant reduction in the bulk flow rate; and 3) the reduction of peak velocity correlated with a reduced PT sound intensity. We thus hypothesize that the flow jet, and not the sinus bulk flow rate, is related to PT in patients with a transverse sinus stenosis.

The suspected cause of the decrease in peak jet velocity post-LP is an alleviation of transverse sinus stenosis as suggested by prior case reports. ${ }^{23-26}$ We were able to directly demonstrate this with MR venography in 1 patient using a blood pool contrast agent, and we believe this study is the first to use MR venography to show an immediate resolution in venous sinus stenosis after LP.

The direct relationship between peak jet velocity and CSF pressure was maintained for patients in this series who met the Dandy criteria for IIH (CSF opening pressure of $>25 \mathrm{~cm} \mathrm{H}_{2} \mathrm{O}$ ) and for patients not meeting the Dandy criteria. Of our subjects who had improvement in their PT after removal of CSF, 5 of 7 had an opening pressure of $\geq 20 \mathrm{~cm} \mathrm{H}_{2} \mathrm{O}$, a threshold for abnormal elevation proposed by Corbett and $\mathrm{Mehta}^{27}$ for patients with a normal body mass index. Of note, venous sinus stenosis was observed in all patients in this series meeting or exceeding the $20-\mathrm{cm}$ $\mathrm{H}_{2} \mathrm{O}$ threshold.

In a prospective trial, Boddu et $\mathrm{al}^{11}$ showed that $\mathrm{PT}$ can be alleviated in patients with IIH with venous sinus stent placement, and our results suggest that broadening this therapy to patients with PT who do not have IIH may warrant consideration, at least for patients with a transverse sinus stenosis whose symptoms improve with LP reduction of CSF pressure. ${ }^{28}$

While this study suggests the flow jet to be critical in the development of sound, the mechanistic link between a flow jet and PT symptoms remains opaque. We hypothesize that the transition into turbulent flow that can occur during the deceleration of these jets immediately "downstream" from the stenosis is a probable cause of the sound that causes PT. ${ }^{29}$ However, other anatomic variables may also play a role, such as sigmoid sinus diverticula, which can sometimes be seen in patients with transverse sinus stenosis.

At first glance, a finding that a reduction in symptoms following LP is not associated with a reduction in flow appears somewhat counterintuitive. Although not statistically significant, our data rather indicate that the flow rate might be slightly increased. On closer consideration however, it is known and expected that a vascular stenosis will, at first, have little effect on volume flow rates while peak velocities in the jet rise (and this feature forms the basis of Doppler sonography evaluation of stenoses of the extracranial carotid arteries). In carotid bruits, it is the disordered flow caused by the jet that is the source of sound, and that would be consistent with our observations reported here for PT. We also note that the reduced intracranial pressure seems to result in improvement in a very focal area of stenosis, and not the entirety of the sinus. In fact, most of the stenoses in this cohort were caused by compression from an arachnoid granulation as opposed to a smooth extrinsic stenosis. This discrepancy may help to explain the disparity between our results and prior work.

We hypothesized that the reduced peak velocities, without concomitant reduction in flow rates, primarily are the result of a reduction in the degree of stenosis. The stenoses caused by intra- 


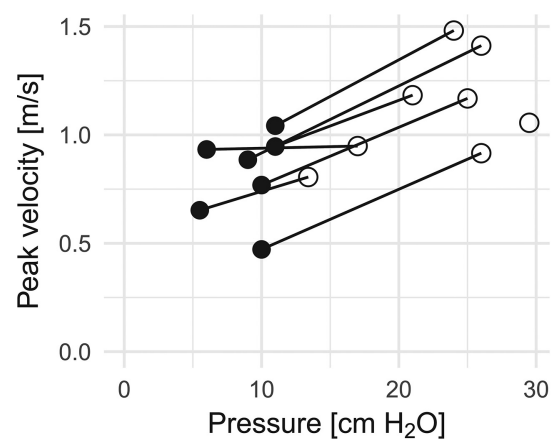

post $\bigcirc$ pre

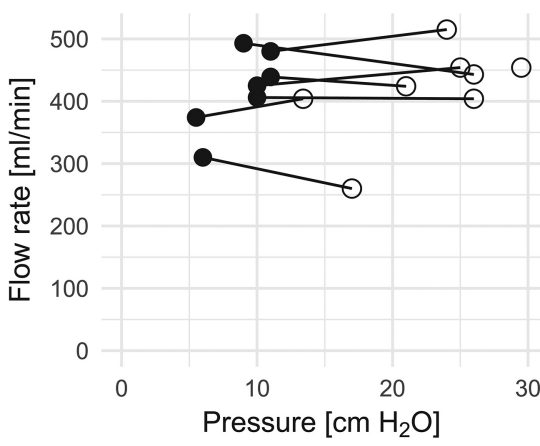

post $\bigcirc$ pre

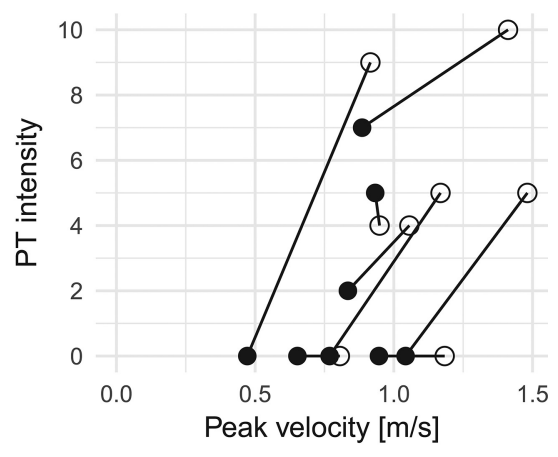

post $\bigcirc$ pre

FIG 4. Lumbar puncture-induced hemodynamic changes for patients with ipsilateral jets. Note that reduced pressure lowered the ipsilateral peak velocity (left panel) without a concomitant reduction in flow rate (middle panel). Furthermore, PT intensity also decreased as the peak velocity was reduced.

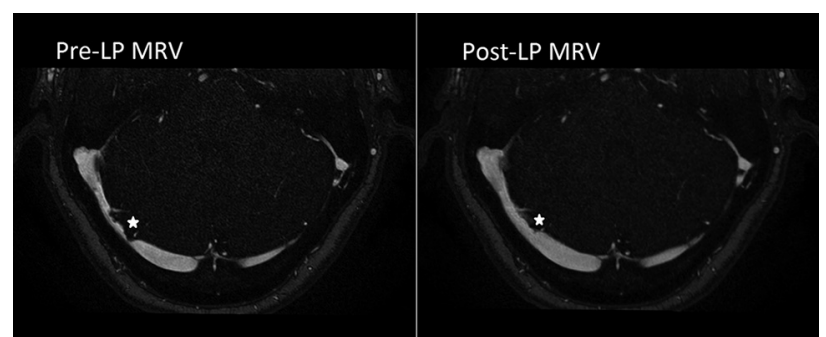

FIG 5. LP-induced change in lumen geometry. The pre-LP MRV lumen is shown on the left side (opening pressure of $25 \mathrm{~cm} \mathrm{H}_{2} \mathrm{O}$ ), whereas the post-LP lumen is seen in the right side (closing pressure of $10 \mathrm{~cm} \mathrm{H} \mathrm{H}_{2} \mathrm{O}$ ). Note the improved transverse sinus stenosis at a prominent arachnoid granulation in the right transverse sinus (star).

cranial hypertension of $>20 \mathrm{~cm} \mathrm{H}_{2} \mathrm{O}$ are alleviated by an LPinduced reduction in intracranial pressure resulting in a concomitant reduction in the jet velocities. This hypothesis is supported by the pre- and post-LP MRA seen in Fig 5, which clearly shows widening of the transverse sinus stenosis after the LP.

\section{CONCLUSIONS}

The objective of this study was to evaluate changes in venous blood flow caused by lowered intracranial pressure in patients with PT after LP to help identify the cause of PT. Our results show an LP-induced reduction in venous peak velocity without a concomitant reduction in flow rate. We hypothesize that the reduction in jet velocity is caused by the alleviation of the transverse stenosis following LP. Our results further show a correlation between peak velocity and PT intensity, suggesting that flow jets are critical in the development of sound.

\section{ACKNOWLEDGMENTS}

We thank Drs Wade Smith and Jonathan Horton for their helpful conversations in developing the concepts behind this work.

Disclosures: Henrik Haraldsson-RELATED: Grant: National Institutes of Health.* David A. Saloner-RELATED: Grant: National Institutes of Health.* Matthew R. Amans-RELATED: Grant: National Institutes of Health, Comments: R21DC016087*; UNRELATED: Consultancy: Covidien, Stryker Neurovascular, Comments: minor financial compensation for consultant work. Alexandra G. Wright-RELATED: Grant: National Institutes of Health, R21DC016087. * *Money paid to the institution.

\section{REFERENCES}

1. Krishnan A, Mattox DE, Fountain AJ, et al. CT arteriography and venography in pulsatile tinnitus: preliminary results. AJNR Am J Neuroradiol 2006;27:1635-38 Medline

2. Liyanage SH, Singh A, Savundra P, et al. Pulsatile tinnitus. J Laryngol Otol 2006;120:93-97 CrossRef Medline

3. Madani G, Connor SE. Imaging in pulsatile tinnitus. Clin Radiol 2009;64:319-28 CrossRef Medline

4. Harvey RS, Hertzano R, Kelman SE, et al. Pulse-synchronous tinnitus and sigmoid sinus wall anomalies: descriptive epidemiology and the idiopathic intracranial hypertension patient population. Otol Neurotol 2014;35:7-15 CrossRef Medline

5. Cognard C, Gobin YP, Pierot L, et al. Cerebral dural arteriovenous fistulas: clinical and angiographic correlation with a revised classification of venous drainage. Radiology 1995;194:671-80 CrossRef Medline

6. Chan CF, Gatehouse PD, Hughes R, et al. Novel technique used to detect swallowing in volume-selective turbo spin-echo (TSE) for carotid artery wall imaging. J Magn Reson Imaging 2009;29:211-16 CrossRef Medline

7. Olin JW, Froehlich J, Gu X, et al. The United States Registry for Fibromuscular Dysplasia: results in the first 447 patients. Circulation 2012;125:3182-90 CrossRef Medline

8. Morris PP, Black DF, Port J, et al. Transverse sinus stenosis is the most sensitive MR imaging correlate of idiopathic intracranial hypertension. AJNR Am J Neuroradiol 2017;38:471-77 CrossRef Medline

9. Morris PP, Lachman N, Black DF, et al. Increased curvature of the tentorium cerebelli in idiopathic intracranial hypertension. AJNR Am J Neuroradiol 2017;38:1789-93 CrossRef Medline

10. Farb RI, Vanek I, Scott JN, et al. Idiopathic intracranial hypertension: the prevalence and morphology of sinovenous stenosis. Neurology 2003;60:1418-24 CrossRef Medline

11. Boddu S, Dinkin M, Suurna M, et al. Resolution of pulsatile tinnitus after venous sinus stenting in patients with idiopathic intracranial hypertension. PLoS One 2016;11:e0164466 CrossRef Medline

12. Asif $\mathrm{H}$, Craven $\mathrm{CL}$, Siddiqui $\mathrm{AH}$, et al. Idiopathic intracranial hypertension: 120-day clinical, radiological, and manometric outcomes after stent insertion into the dural venous sinus. J Neurosurg 2018;129:723-31 CrossRef Medline

13. Dinkin MJ, Patsalides A. Venous sinus stenting in idiopathic intracranial hypertension: results of a prospective trial. J Neuroophthalmol 2017;37:113-21 CrossRefMedline

14. Liu KC, Starke RM, Durst CR, et al. Venous sinus stenting for reduction of intracranial pressure in IIH: a prospective pilot study. $\mathrm{JNeu}$ rosurg 2017;127:1126-33 CrossRef Medline

15. Kao E, Kefayati S, Amans MR, et al. Flow patterns in the jugular veins of pulsatile tinnitus patients. J Biomech 2017;52:61-67 CrossRef Medline 
16. Kefayati S, Amans M, Faraji F, et al. The manifestation of vortical and secondary flow in the cerebral venous outflow tract: an in vivo MR velocimetry study. J Biomech 2017;50:180 - 87 CrossRef Medline

17. Acevedo-Bolton G, Amans MR, Kefayati S, et al. Four dimensional magnetic resonance velocimetry for complex flow in the jugular vein. Quant Imaging Med Surg 2015;5:635-37 CrossRef Medline

18. Smith JL. Whence pseudotumor cerebri? J Clin Neuroophthalmol 1985;5:55-56 Medline

19. Ittrich H, Peldschus K, Raabe N, et al. Superparamagnetic iron oxide nanoparticles in biomedicine: applications and developments in diagnostics and therapy. Rofo 2013;185:1149-66 CrossRef Medline

20. Weinstein JS, Varallyay CG, Dosa E, et al. Superparamagnetic iron oxide nanoparticles: diagnostic magnetic resonance imaging and potential therapeutic applications in neurooncology and central nervous system inflammatory pathologies: a review. J Cereb Blood Flow Metab 2010;30:15-35 CrossRef Medline

21. Hope MD, Hope TA, Zhu C, et al. Vascular imaging with ferumoxytol as a contrast agent. AJR Am J Roentgenol 2015;205:W366-73 CrossRef Medline

22. Heiberg E, Sjögren J, Ugander M, et al. Design and validation of Segment: freely available software for cardiovascular image analysis. BMC Med Imaging 2010;10:1 CrossRef Medline

23. Scoffings DJ, Pickard JD, Higgins JN. Resolution of transverse sinus stenoses immediately after CSF withdrawal in idiopathic intracranial hypertension. J Neurol Neurosurg Psychiatry 2007;78:911-12 CrossRef Medline

24. King JO, Mitchell PJ, Thomson KR, et al. Manometry combined with cervical puncture in idiopathic intracranial hypertension. Neurology 2002;58:26-30 CrossRef Medline

25. Baryshnik DB, Farb RI. Changes in the appearance of venous sinuses after treatment of disordered intracranial pressure. Neurology 2004; 62:1445-46 CrossRef Medline

26. Onder H, Gocmen R, Gursoy-Ozdemir Y. Reversible transverse sinus collapse in a patient with idiopathic intracranial hypertension. BMJ Case Rep 2015;2015 CrossRef Medline

27. Corbett JJ, Mehta MP. Cerebrospinal fluid pressure in normal obese subjects and patients with pseudotumor cerebri. Neurology 1983;33: 1386-88 CrossRef Medline

28. Lenck S, Labeyrie MA, Vallee F, et al. Stent placement for disabling pulsatile tinnitus caused by a lateral sinus stenosis: a retrospective study. Oper Neurosurg (Hagerstown) 2017;13:560-65 CrossRef Medline

29. Baomin L, Yongbing S, Xiangyu C. Angioplasty and stenting for intractable pulsatile tinnitus caused by dural venous sinus stenosis: a case series report. Otol Neurotol 2014;35:366-70 CrossRef Medline 